DE

M E D I C I N A

T R O P I C A L

$\mathrm{DE}$

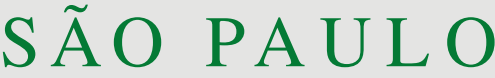

JOURNAL OF THE SÃO PAULO INSTITUTE OF TROPICAL MEDICINE

'Universidade Federal do Pará, Faculdade de Farmácia, Laboratório de Farmacocinética de Antimaláricos, Belém, Pará, Brazil

Correspondence to: José Luiz Fernandes Vieira

Universidade Federal do Pará,

Faculdade de Farmácia, Laboratório de

Farmacocinética de Antimaláricos, Rua

Augusto Corrêa, 1, Campus Universitário do Guamá, CEP 66075-110, Belém, PA, Brazil

Tel: +55 $913201-8823$

E-mail: jvieira@ufpa.br

Received: 1 August 2018

Accepted: 24 September 2018

\section{Levels of primaquine and carboxyprimaquine in patients with malaria vivax from the Brazilian Amazon basin}

\author{
Amanda Gabryelle Nunes Cardoso Mello', Michelle Valéria Dias Ferreira \\ Vieira1, Luann Wendel Pereira de Sena', Thiago Portal da Paixão', Ana Carla \\ Godinho Pinto', Daniella Paternostro de Araújo Grisólia1, Margareth Tavares \\ Silva', José Luiz Fernandes Vieira'
}

KEYWORDS: Malaria. Hypnozoite. Primaquine

\title{
INTRODUCTION
}

In the last two years, a substantial increase in malaria vivax burden occurred in several municipalities of the Brazilian Amazon basin ${ }^{1,2}$. The reasons for the unexpected increase of cases are unclear, and health authorities are investigating several factors, including the relapse of hypnozoites due to resistance or to reduced sensitivity of $P$. vivax strains to primaquine, as well as the inadequate exposure to this drug due to low-quality of commercial formulations, use of sub-therapeutic doses, non-compliance with the prescribed regimen and variations in the kinetic disposition of primaquine ${ }^{3-7}$.

Despite the fact that tafenoquine has been approved in July 2018 by the United States' Food and Drug Administration for the radical cure of vivax infections in patients aged 16 and older, primaquine is still the only available drug to eliminate hypnozoites from the human host in several endemic areas ${ }^{8}$. Health authorities recommend the supervised administration of this drug. However, there are logistic difficulties in the riverside communities of the Amazon basin. Compliance with prescribed regimen is also a matter of interest in this endemic setting. A feasible method to assess the 
exposure of the infecting parasite population to antimalarial drugs is the measure of their levels in biological fluids ${ }^{9}$. There are limitations to interpret primaquine blood levels in studies of therapeutic efficacy including the drug's short half-life, pharmacological and toxicological effects due to hydroxylated metabolites, and the fact that the therapeutic efficacy depends on the amount of drug that reaches hepatocytes, which is related to the total dose administered, but not with frequency or duration of exposure. Finally, there is a high variation in the pharmacokinetics of the drug amongst and in individuals ${ }^{10-14}$.

The measurement of blood levels of primaquine and its main metabolite only once during treatment may give a reliable assessment of exposure of the infecting parasite population to the drug. Moreover, the association of drug blood levels with clinical and parasitological outcomes provides insight on the effectiveness of blood levels of primaquine against hypnozoites. To date, the exposure to primaquine and its carboxyl metabolite has not been assessed in malaria patients in the Brazilian Amazon basin. Therefore, the aim of this study was to estimate the levels of primaquine and carboxyprimaquine in whole blood samples of patients with malaria vivax treated with chloroquine and an abbreviated regimen of primaquine $(0.5 \mathrm{mg} / \mathrm{kg} / \mathrm{d}$ for $7 \mathrm{~d})$, with adequate clinical and parasitological outcomes after a 180 days of follow-up.

\section{MATERIAL AND METHODS}

\section{Study site and patients}

This study is a one-arm prospective evaluation of exposure to primaquine during treatment of malaria vivax carried out from January 2015 to December 2016 at the Unidade Basica de Saude (Basic Health Unit) of Anajas, $\mathrm{PA}$, a municipality in Marajo Island in the Brazilian Amazon basin $\left(0^{\circ} 59^{\prime} 21^{\prime \prime} \mathrm{S}\right.$ and $\left.49^{\circ} 56^{\prime} 24^{\prime \prime} \mathrm{W}\right)$. The transmission of the disease in Anajas is intense with some seasonal variation and P. vivax accounts for approximately $85 \%$ of cases. In the last years, the municipality reported the highest number of cases to the National Surveillance System, in the State of Para.

Inclusion criteria for enrollment in the study were: adult male $>18$ years old with mono-infection by $P$. vivax detected by microscopy, axillary temperature above $37^{\circ} \mathrm{C}$ or history of fever during the past $24 \mathrm{~h}$ and being able to swallow the oral medication. The exclusion criteria included patients with signs and symptoms of severe disease (jaundice, pulmonary or renal impairment, severe anemia, altered levels of consciousness), glucose-6-phosphate dehydrogenase deficiency, mixed infection detected by microscopy, parasitemia over $5 \%$, overweight (or underweight), presence of fever due to diseases other than malaria, or other known underlying chronic or severe diseases, history of hypersensitivity reaction to chloroquine or primaquine and use of antimalarial drugs in the previous 90 days.

\section{Treatment and follow-up}

Each patient received multiple oral doses regimen of chloroquine $(10 \mathrm{mg} / \mathrm{kg}$ on day 0 and $7.5 \mathrm{mg} / \mathrm{kg}$ on days 1 and 2) co-administered with primaquine $(0.5 \mathrm{mg} / \mathrm{kg} / \mathrm{d}$ for 7 days, as $13.2 \mathrm{mg}$ of primaquine phosphate tablets) ${ }^{8}$. The primaquine dose was adjusted according to body weight. All doses of medicines were administered under the supervision of a qualified member of the research team. The study patients were observed for $30 \mathrm{~min}$ after the medicine administration for the the observation of adverse reactions or vomiting. Patients were requested to return for blood sampling and clinical evaluation on days 1, 3, 7, 14, 21 and 28 . Then, the study patients were monitored by passive surveillance at the health facility for a period of 180 days. Moreover, records from the National Malaria Database (SIVEP-Malaria) were investigated to identify any other malaria test performed during the study period in any of the study patients. Clinical and parasitological outcomes were based on the standardized WHO protocols ${ }^{15}$.

\section{Sample size}

The sample size was based on previous studies of efficacy conducted in this endemic setting, which has reported a failure rate of about $2 \%$ to the standard treatment of malaria vivax, with a confidence level of $95 \%$ and precision of $5 \%$. Thus, a minimum sample of 30 patients was required for the study $2,7,15,16$.

\section{Evaluation of efficacy}

The parasite count was performed in Giemsa-stained thick films every day until the negativity of parasitemia, and on days 1, 3, 7, 14, 21 and 28. An experienced microscopist examined the blood films using 100X (oil immersion) objectives. The parasite density was expressed as the number of parasites per $\mu \mathrm{L}$ of blood, estimated according to the number of parasites per 200 white blood cells, considering a total white blood cell count of 8,000 . The limit of detection of the parasites was $40 / \mu \mathrm{L}^{15}$.

\section{Blood sample collection}

Venous blood samples $(4 \mathrm{~mL})$ were taken from each patient for primaquine and carboxyprimaquine 
measurements at baseline (D0) and on days 1, 3 and 7. All blood samples were collected approximately $3 \mathrm{~h}$ after the primaquine intake. Blood samples were immediately stored at $-80{ }^{\circ} \mathrm{C}$ until analysis.

\section{Measurement of primaquine and carboxyprimaquine}

Primaquine and carboxyprimaquine were measured by a reversed-phase HPLC system with a diode array detector (Flexar System - Perkin Elmer Inc., Boston, MA, USA) after liquid-liquid extraction from the whole blood samples with methyl tert-butyl ether at $\mathrm{pH} 3$. The separation was carried out in a reversed-phase column RP- $18,15 \mathrm{~cm} \times 4 \mathrm{~mm}$ i.d. (PerkinElmer Inc.). The mobile phase consisted of acetonitrilephosphate buffer, pH 3.5 (30:70) eluate at $1.0 \mathrm{~mL} / \mathrm{min}$. Analytes were recorded at $254 \mathrm{~nm}$. Quinine $(1.0 \mu \mathrm{g} / \mathrm{mL})$ was used as an internal standard ${ }^{17}$. The method was linear in the range from $50 \mathrm{ng} / \mathrm{mL}$ to $900 \mathrm{ng} / \mathrm{mL}$. The limit of detection was $20 \mathrm{ng} / \mathrm{mL}$ and the limit of quantification was $30 \mathrm{ng} / \mathrm{mL}$ for both analytes. The mean coefficients of variation within a day and day-to-day were $12.3 \%$ and $16.1 \%$, respectively. The mean recovery of primaquine from whole blood was $87.3 \%$. For carboxyprimaquine, the mean coefficients of variation within a day and day-to-day were $14.1 \%$ and $17.4 \%$, respectively. The mean recovery was $88.5 \%$. The stability of primaquine $(100 \mathrm{ng} / \mathrm{mL})$ and carboxyprimaquine in whole blood samples were tested by spiking the analytes in the biological matrix, which was stored for 120 days at $-80^{\circ} \mathrm{C}$. There were no significant interferences of mefloquine, chloroquine, desethyl-chloroquine, carboxy-mefloquine, and acetaminophen in the detection of both analytes.

\section{Data analysis}

Data were analyzed by non-parametric methods. The Kruskal-Wallis H-test was used to compare the levels of primaquine and carboxyprimaquine amongst the days of study. All p-values were two-tailed, and $\mathrm{p}<0.05$ was considered significant. Statistical analyses were performed with STATISTICA software package (Version 7.0, Stat Soft Inc., 2004, Tulsa, USA).

\section{Ethical statement}

The ethics committee of the Instituto de Ciencias da Saude (Health Science Institute) of the Federal University of Para has reviewed and approved the study protocol (CONEP N $\mathrm{N}^{\circ}$ 2.770.805). All patients enrolled in the study were informed about the goals, as well as the risks and benefits of the study. All patients provided written informed consent before entering the study.

\section{RESULTS}

A total of 40 patients were recruited for the study and 140 whole blood samples were collected and analyzed for primaquine and carboxyprimaquine. A total of 20 blood samples were not analyzed due to the loss of patients' follow up. The baseline characteristics of patients are presented in Table 1.

Table 1 - Baseline characteristics of patients

\begin{tabular}{lc}
\hline Characteristic & Patients $(\mathrm{n}=40)$ \\
\hline Ages, years & $29(16)$ \\
Weight, kg & $63(12)$ \\
Parasite count on D0, mm ${ }^{3}$ & $1920(1438)$ \\
Parasite clearance, $\mathrm{h}$ & $36(12)$ \\
Fever clearance, $\mathrm{h}$ & $18(12)$ \\
Previous episodes of infection, \% & 100 \\
Hemoglobin, g/dL & $11.4(3.1)$ \\
Hematocrit, \% & $36(12.1)$ \\
Erythrocytes count, $10^{6}$ & $4.3(0.62)$ \\
White blood cells, mm ${ }^{3}$ & $6,180(1210)$ \\
Creatinine, mg/dL & $0.6(0.3)$ \\
Aspartate aminotransferase, U/l & $28(13)$ \\
Alanine aminotransferase, U/l & $43(12)$
\end{tabular}

Results are expressed as mean (standard deviation) and percentage

Study patients showed low parasite density as well as mild signs and symptoms of malaria. There were no reports of serious adverse reactions or vomiting during treatment. The average time of parasite clearance from the peripheral blood was $36 \mathrm{~h}$. The local health facility and the Malaria National Surveillance System did not report reappearance of parasites in the blood of study patients in the 180 days of follow-up.

The average time for blood sampling was $3.0(0.5) \mathrm{h}$. All patients had undetectable levels of both primaquine and carboxyprimaquine on day 0 . The levels of primaquine in whole blood samples ranged from $40-238 \mathrm{ng} / \mathrm{mL}$, $42-196 \mathrm{mg} / \mathrm{mL}$ and $42-150 \mathrm{ng} / \mathrm{mL}$ on days 1,3 and 7 , respectively. There was no significant difference in blood levels of primaquine amongst the days of the study $(\mathrm{H}=1.05 ; \mathrm{p}=0.589)$. The levels of carboxyprimaquine ranged from $87-234 \mathrm{ng} / \mathrm{mL}, 96-252 \mathrm{ng} / \mathrm{mL}$ and $74-448 \mathrm{ng} / \mathrm{mL}$ on days 1,3 and 7 , respectively. The levels of carboxyprimaquine were similar between days 1 and 3 , but they were significantly lower than on day $7(\mathrm{H}=13.27$; $\mathrm{p}=0.001)$ (Table 2). 
Table 2 - Whole blood levels of primaquine and carboxyprimaquine.

\begin{tabular}{lcc}
\hline Days & $\begin{array}{c}\text { Primaquine } \\
(\mathrm{n}=40) \\
\mathrm{ng} / \mathrm{mL}\end{array}$ & $\begin{array}{c}\text { Carboxyprimaquine } \\
(\mathrm{n}=40) \\
\mathrm{ng} / \mathrm{mL}\end{array}$ \\
\hline D0 & $\mathrm{nd}$ & $\mathrm{nd}$ \\
D1 & $95(53-167)$ & $150(102-156)$ \\
D3 & $78(69-133)$ & $161(106-190)$ \\
D7 & $70(63-99.8)$ & $231(170-284)$ \\
\hline
\end{tabular}

Results are expressed as median and interquartile range. $\mathrm{nd}=$ not detected

\section{DISCUSSION}

Primaquine is used to eliminate hypnozoites from the human host, which are responsible for the relapses weeks to months after the primary infection, contributing to the malaria vivax burden in the Amazon basin ${ }^{12,18}$. Relapses may occur as early as 16 days up to 3 years after the initial infection, even if the blood stage was adequately treated ${ }^{19}$. In the study, the follow-up was adapted to the regional pattern of relapse of $P$. vivax in Brazil, of about three months after the initial attack ${ }^{20-22}$. The abbreviated regimen of primaquine was recommended by the Brazilian Malaria Control Programsince the 1990s to improve the tolerability and the compliance with treatment ${ }^{23}$.

Several confounding factors were controlled in the study, allowing the reliable estimation of exposure of the parasites to primaquine, such as the supervised administration of the drug, the validation parameters of the analytical method for both compounds were adequate and the time of blood sampling was carefully monitored. Moreover, the use of whole blood samples as the biological matrix was based on previous studies that reported a similar concentrationtime profile of both, the parent compound and the carboxyl metabolite in whole blood and in plasma samples of healthy volunteers ${ }^{9,14,24}$.

The days and time for blood sampling were based on the pharmacokinetic parameters of primaquine and carboxyprimaquine. The parent drug is virtually completely absorbed, has a plasma elimination half-life of 4-9 h, peak of plasma concentrations are reached within $1-3 \mathrm{~h}$, and it does not accumulate in the course of chronic doses of $15 \mathrm{mg}$. Urinary excretion of primaquine is low, with most of the dose recovered as metabolites ${ }^{13,14,24,25}$. The levels of primaquine were similar amongst the days of study, corroborating the lack of significant accumulation of the drug in body components. The highest concentrations were found on day 3 , in agreement with the potential changes in pharmacokinetic parameters of the drug due to concurrent administration of chloroquine. Moreover, the parasites in blood and the change of parasites clearance under chronic doses may interfere with blood levels of primaquine $^{14,17,24-27}$.

Despite the high variation in blood levels of primaquine among the participants of the study, the normalization of data by dosing regimen provided similar results to those reported in healthy volunteers and in patients with malaria vivax from different endemic areas, such as Thailand and India $^{13,14,24-26}$.

Carboxyprimaquine is the major metabolite generated via metabolism by MAO-A ${ }^{13,27}$. The metabolite does not show pharmacological or toxicological activities ${ }^{13,28,29}$.

There are significant differences in the pharmacokinetic profile of the metabolite compared to the parent drug. Carboxyprimaquine has a longer plasma elimination halflife $(\sim 15 \mathrm{~h})$, peak of plasma levels are reached within 4-12 h and may be up to 10 times higher than the parent compound, the area under the curve is considerably greater than the parent drug, and its more polar characteristic suggests a limited distribution with high levels in plasma water ${ }^{13,30}$. Based on pharmacokinetic parameters, carboxyprimaquine may be considered a potential candidate for the assessment of exposure to primaquine.

The main limitation of the study was the probable underestimation of carboxyprimaquine levels as blood sampling was based on time to reach plasma peak concentrations of primaquine $(3 \pm 1 \mathrm{~h})$, rather than the carboxyl metabolite $(7 \pm 4 \mathrm{~h})^{13,30}$.

Overall, the levels of primaquine and carboxyprimaquine agreed with the pharmacokinetic profile of both compounds reported in studies performed in different endemic settings. Data provided a reliable estimation of exposure of the infecting parasite population to primaquine during treatment of malaria vivax in a population from the Brazilian Amazon basin which can be useful to strengthen the ongoing surveillance of primaquine efficacy in this endemic setting. Based on the regional pattern of relapse, blood levels of primaquine found in this study were effective against local circulating $P$. vivax strains.

\section{CONFLICT OF INTERESTS}

The authors declare that there is no conflict of interests.

\section{AUTHORS' CONTRIBUTIONS}

AGNCM, MVDFV, JLFV attended the guidance and supervision of fieldwork, interpretation of results and development of the manuscript; AGNCM, JLFV, LWPS,TPP, ACGP,DPAG, MTS participated in designing 
the study, data collection, data analysis and interpretation of results; AGCNM, JLFV, ACGP, MTS cooperating with the interpretation of results and manuscript preparation. All authors read and approved the manuscript.

\section{REFERENCES}

1. Organización Panamericana de la Salud. Organización Mundial de la Salud. Actualización epidemiológica: aumento de malária em las Américas, 30 de enero de 2018. Washington: OPS/OMS; 2018.

2. World Health Organization. World malaria report 2017. Geneva: WHO; 2017.

3. Thomas D, Tazerouni H, Sundararaj KG, Cooper JC. Therapeutic failure of primaquine and need for new medicines in radical cure of Plasmodium vivax. Acta Trop. 2016;160:35-8.

4. Phanouvong S, Dijiba Y, Vijaykadga S, Raymond C, Krech L, Lukulay $\mathrm{P}$, et al. The quality of antimalarial medicines in eastern Thailand: a case study along the Thai-Cambodian border. Southeast Asian J Trop Med Public Health. 2013;44:363-73.

5. Pukrittayakamee S, Chantra A, Simpson JA, Vanijanonta S, Clemens R, Looareesuwan S, et al. Therapeutic responses to different antimalarial drugs in vivax malaria. Antimicrob Agents Chemother. 2000;44:1680-5.

6. Almeida ED,Vieira JL. Factors associated with non-adherence to the treatment of vivax malaria in a rural community from the Brazilian Amazon Basin. Rev Soc Bras Med Trop. 2016;49:248-51.

7. Santana Filho FS, Arcanjo AR, Chehuan YM, Costa MR, Martinez-Espinosa FE, Vieira JL, et al. Chloroquine-resistant Plasmodium vivax, Brazilian Amazon. Emerg Infect Dis. 2007;13:1125-6.

8. World Health Organization. Guidelines for the treatment of malaria. $3^{\text {rd }}$ ed. Geneva: WHO; 2015.

9. World Health Organization. Methods and techniques for assessing exposure to antimalarial drugs in clinical field studies. Geneva: WHO; 2011.

10. Duarte EC, Pang LW, Ribeiro LC, Fontes CJ. Association of subtherapeutic dosages of a standard drug regimen with failures in preventing relapses of vivax malaria. Am J Trop Med Hyg. 2001;65:471-6.

11. Carmona-Fonseca J, Alvarez G, Blair S. Malaria por Plasmodium vivax: curación del ataque agudo con tres dosis diferentes de primaquina y dosis fija de cloroquina. Antioquia, Colombia, 2003-2004. Biomedica. 2006;26:353-65.

12. Burgoine KL, Bancone G, Nosten F. The reality of using primaquine. Malar J. 2010;9:376.

13. Mihaly GW, Ward SA, Edwards G, Orme M, Breckenridge AM. Pharmacokinetics of primaquine in man: identification of the carboxylic-acid derivative as a major plasma metabolite. Br J Clin Pharmacol. 1984;17:441-6.
14. Bhatia SC, Saraph YS, Revankar SN, Doshi KJ, Bharucha ED, Desai ND, et al. Pharmacokinetics of primaquine in patients with Plasmodium vivax malaria. Eur J Clin Pharmacol. 1986;31:205-10.

15. World Health Organization. Malaria surveillance, monitoring \& evaluation: a reference manual. Geneva: WHO; 2018.

16. Gomes MS, Vieira JL, Machado RL, Nacher M, Stefani, A, Musset L, et al. Efficacy in the treatment of malaria by Plasmodium vivax in Oiapoque, Brazil, on the border with French Guiana: the importance of control over external factors. Malar J. 2015;14:402.

17. Dua VK, Kar PK, Sarin R, Sharma VP. High-performance liquid chromatographic determination of primaquine and carboxyprimaquine concentrations in plasma and blood cells in Plasmodium vivax malaria cases following chronic dosage with primaquine. J Chromatogr B Biomed Appl. 1996;675:93-8.

18. Fernando D, Rodrigo C, Rajapakse S. Primaquine in vivax malaria: an update and review on management issues. Malar J. 2011;10:351.

19. Chu CS, White NJ. Management of relapsing Plasmodium vivax malaria. Expert Rev Anti Infect Ther. 2016;14:885-900.

20. Boulos M, Amato Neto V, Dutra AP, Di Santi SM, Shiroma M. Análise da freqüência de recaídas de malária por Plasmodium vivax em região não endêmica (São Paulo, Brasil). Rev Inst Med Trop Sao Paulo. 1991;33:143-6.

21. Orjuela-Sánchez P, Silva NS, Silva-Nunes M, Ferreira MU. Recurrent parasitemias and population dynamics of Plasmodium vivax polymorphisms in rural Amazonia. Am J Trop Med Hyg. 2009;81:961-8.

22. Pedro RS, Guaraldo L, Campos DP, Costa AP, Daniel-Ribeiro CT, Brasil P.Plasmodium vivax malaria relapses at a travel medicine centre in Rio de Janeiro,a non-endemic area in Brazil. Malar J. 2012;11:245.

23. Brasil. Ministério da Saúde. Secretaria de Vigilância em Saúde. Departamento de Vigilância Epidemiológica. Guia prático de tratamento da malária no Brasil. Brasília: Ministério da Saúde; 2010.

24. Singhasivanon V, Sabcharoen A, Attanath P, Chongsuphajaisiddhi T, Diquet B, Turk P. Pharmacokinetics of primaquine in healthy volunteers. Southeast Asian J Trop Med Public Health. 1991;22:527-33.

25. Ward SA, Mihaly GW, Edwards G, Looareesuwan S, Phillips RE, Chanthavanich $\mathrm{P}$, et al. Pharmacokinetics of primaquine in man. II. Comparison of acute vs chronic dosage in Thai subjects. Br J Clin Pharmacol. 1985;19:751-5.

26. Edwards G, McGrath CS, Ward SA, Supanaranond W, Pukrittayakamee S, Davis TM, et al. Interactions among primaquine, malaria infection and other antimalarials in Thai subjects. Br J Clin Pharmacol. 1993;35:193-8.

27. Pukrittayakame S, Tarning J, Jittamala $P$, Charunwatthana $P$, Lawpoolsri S, Lee SJ, et al. Pharmacokinetic interactions 
between primaquine and chloroquine. Antimicrob Agents Chemother. 2014;58:3354-9.

28. Bangchang KN, Karbwang J, Back DJ. Primaquine metabolism by human liver microsomes: effect of other antimalarial drugs. Biochem Pharmacol. 1992;44:587-90.

29. Peters W, Robinson BL. The activity of primaquine and its possible metabolites against rodent malaria. In: Wernsdorfer WH, Trigg PI, editors. Primaquine: pharmacokinetics, metabolism, toxicity and activity. . Chichester: John Wiley; 1987. p.93-101.
30. Kim YR, Kuh HJ, Kim MY, Kim YS, Chung WC, Kim SI, et al. Pharmacokinetics of primaquine and carboxyprimaquine in Korean patients with vivax malaria. Arch Pharm Res. 2004;27:576-80. 